\title{
Effect of the Microenvironment on Mesenchymal Stem Cell Paracrine Signaling: Opportunities to Engineer the Therapeutic Effect
}

\author{
Gina D. Kusuma, ${ }^{1, *}$ James Carthew, ${ }^{1,{ }^{*}}$ Rebecca Lim, ${ }^{2,3}$ and Jessica E. Frith ${ }^{1}$
}

Cues from the extracellular environment, including physical stimuli, are well known to affect mesenchymal stem cell (MSC) properties in terms of proliferation and differentiation. Many therapeutic strategies are now targeting this knowledge to increase the efficacy of cell therapies, typically employed to repair tissue functions in the event of injury, either by direct engraftment into the target tissue or differentiation into mature tissues. However, it is now envisioned that harnessing the repertoire of factors secreted by MSCs (termed the secretome) may provide an alternate to these cell therapies. Of current interest are both direct protein secretions and two major subpopulations of bioactive extracellular vesicles (EVs), namely exosomes and microvesicles. EVs released by MSCs are reflective of their cells of origin, able to impact upon the activities of other cells in the local microenvironment, making the rational design of MSC paracrine activities an encouraging strategy to reproducibly modulate cell therapies. The precise mechanisms by which the secretome is modulated by the microenvironment, however, remain elusive. Controlling MSC growth conditions with oxygen tension, growth factor composition, and mechanical properties may serve to directly influence paracrine activity. Our growing understanding implicates components of the mechanotransduction machinery in translating both mechanical and chemical cues from the environment into alterations in gene regulation and varied paracrine activity. As technologies are developed to manufacture MSCs, advances in bioengineering and novel insight of how the extracellular environment affects MSC paracrine activity will play a pivotal role in the generation of widespread, successful, clinical MSC therapies.

Keywords: mesenchymal stem cell, paracrine signaling, tissue engineering, exosomes, microenvironment

\section{Introduction}

Q TEM Cell therapies are typically employed to repair $\checkmark$ tissue functions in the event of injury, either by direct engraftment into the target tissue and differentiation into mature tissue cell types or as vehicles to deliver bioactive factors [1]. Mesenchymal stem cells (MSCs) hold significant promise for tissue engineering and regenerative medicine applications due to their unique properties to support these applications, such as extensive proliferation ability, multilineage differentiation capacity, ease of isolation from various human tissues, immune-privileged status, and paracrine activity [2-5]. MSCs are multipotent cells, originally identified in adult bone marrow (BM), which replicate as undifferentiated cells and have the potential to differentiate into the mesenchymal lineage [6]. The nomenclatures for mesenchyme-like cells are variously referred to as "mesenchymal stem cells" or "mesenchymal stromal cells" or "multipotent stromal cells," and the acronym "MSC" is now generally used to identify this class of cells. BMMSCs are the most extensively studied, although they also have been isolated from tissues such as cord blood, peripheral blood, adipose tissue, umbilical cord, amniotic fluid, fetal tissues, placenta, dental pulp, synovial fluid, skeletal muscle, periosteum, lung, and cartilage [7-14]. To assist in comparison between different laboratories, the International Society of Cellular Therapy set the minimal criteria to define MSCs as plastic adherent and expressing CD105, CD73, and CD90 without expression of CD45, CD34, CD14 or CD11b, CD79 $\alpha$ or CD19, and HLA-DR. MSCs must also be able to differentiate in vitro into osteoblasts, adipocytes, and chondrocytes [15].

MSC applications in tissue engineering are strongly associated with the advances in biocompatible materials, which can increase cell survival and guide cell differentiation

Departments of ${ }^{1}$ Materials Science and Engineering and ${ }^{2}$ Obstetrics and Gynecology, Monash University, Clayton, Victoria, Australia.

${ }^{3}$ The Ritchie Centre, Hudson Institute of Medical Research, Clayton, Victoria, Australia.

*These two authors contributed equally to this work. 
in vivo. As a result, adult MSCs have been incorporated in various tissue engineering therapies ranging from cardiac repair, skeletal tissue repair, invertebral disc repair, cartilage and bone tissue regeneration, and many others [16-20]. In the last decade, the development of MSC-based cell therapies has been influenced by our ever-expanding knowledge of the biological characteristics of these cells that contribute to their therapeutic effects. The hypothesis that MSCs have ongoing therapeutic effects in damaged tissues or organs has been heavily challenged by several studies that revealed very low engraftment of cells following systemic administration of MSCs [21-25]. Despite the initial model of MSCs homing into injury sites and differentiating into multiple cell types, there is a general consensus that another mechanism must exist by which MSCs exercise their therapeutic effect, and paracrine signaling has emerged as a critical player.

MSCs release a plethora of biologically active factors (ie, cytokines, chemokines, growth factors, and miRNAs), which have profound effects on local cellular dynamics. These bioactive factors are decision-makers of cell fate, and MSCs are no exception to this role where the core stem cell properties, for example, self-renewal, differentiation, and tissue engraftment, are largely influenced by the local microenvironment. This multitude of paracrine factors form part of a complex network that confers stability to the cells as well as amplification of regenerative response [26].
This has resulted in numerous investigations into the factors that make up MSC paracrine signaling, which could perhaps exert some of the beneficial effects following stem cell transplantation. It has been proposed that MSCs may act as injury drug stores by secreting bioactive molecules and regulating local immune response to establish a regenerative microenvironment and subsequently repair the injured tissues [27]. As such, many models of MSC-based tissue repair now heavily rely upon the influence of MSC paracrine signaling and it is envisioned that either delivery of MSCs to facilitate paracrine factor provision or perhaps direct administration of collected MSC paracrine outputs could form the basis of future MSC therapies. In this review, we discuss critical factors that influence MSC paracrine signaling and present future biomaterial strategies to engineer precise microenvironmental conditions for successful tissue engineering applications.

\section{The MSC Secretome}

The repertoire of factors secreted by MSCs is called the secretome, consisting of a diverse range of cytokines, chemokines, angiogenic factors, and growth factors [28] (Fig. 1). The secretome can impact the activities of other cells in the local microenvironment. It has been suggested that up to $80 \%$ of the therapeutic effect of adult MSCs is

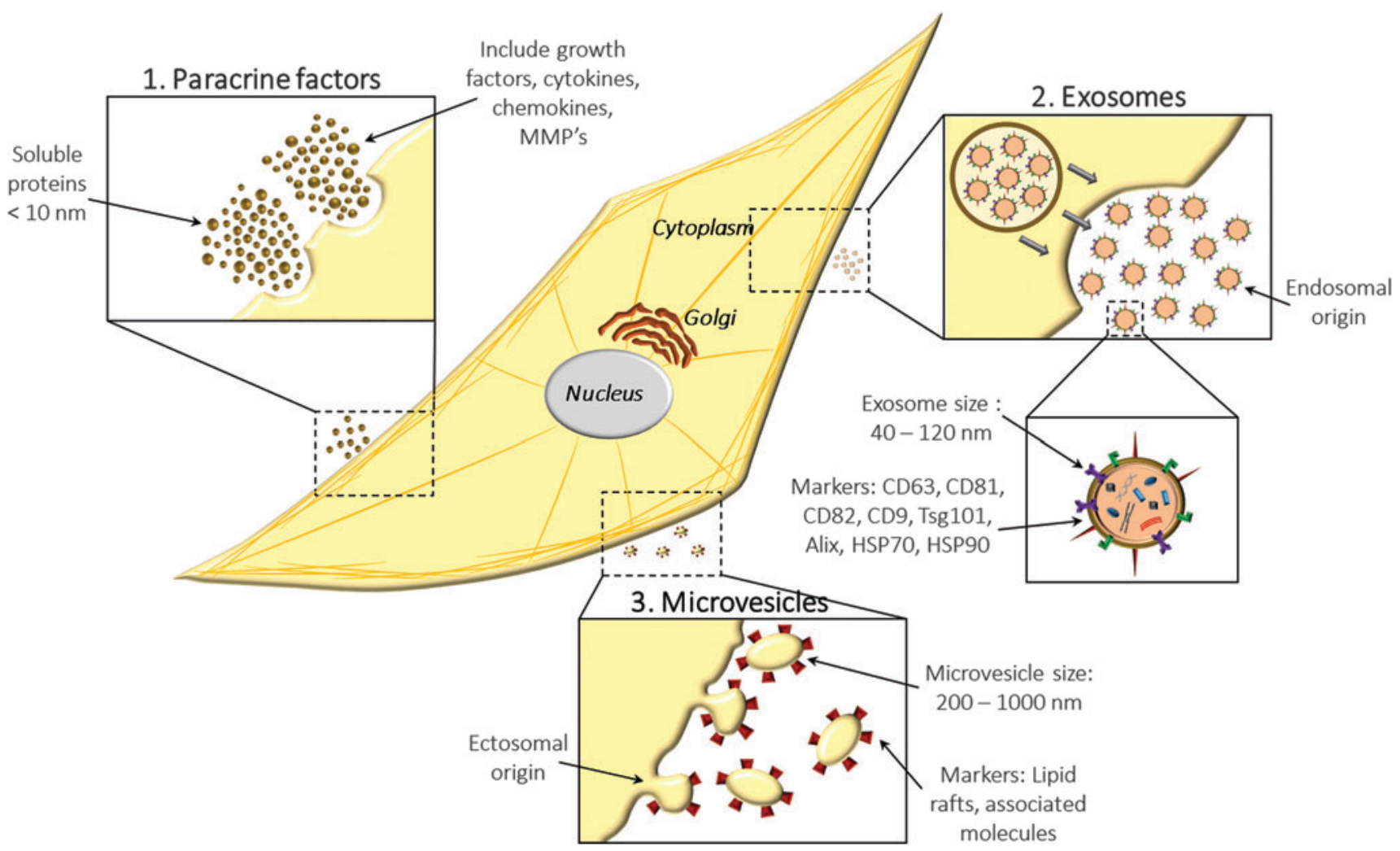

FIG. 1. An overview of MSC secretome. Schematic representation of biologically active substances released by MSCs. A variety of paracrine factors made up of soluble proteins are secreted through fusion of secretory granules with the plasma membrane. Cells also shed bioactive factors packaged in extracellular vesicles. Microvesicles are shed directly from the plasma membrane by outward budding and are relatively large (200-1,000 nm). Exosomes are released by fusion of multivesicular bodies with the plasma membrane and are more homogenous in size (40-120 nm). Exosomes express cell surface markers such as CD63, CD81, CD82, CD9, Tsg101, Alix, HSP70, and HSP90 and contain materials such as miRNAs, mRNAs, lipids, and proteins. MSCs, mesenchymal stem cells. Color images available online at www.liebertpub.com/scd 
through such paracrine-mediated actions, and proteins secreted by MSCs have been documented to be antimicrobial, antifibrotic, and proregenerative, exerting effects on processes such as angiogenesis, proliferation, differentiation, immune modulation, wound healing, bone regeneration, and kidney and cardiac regeneration [29-34]. We have populated numerous research articles to summarize a variety of paracrine factors released by adult human MSCs and their subsequent reparative effects (Table 1). MSCs have been shown to exert a cytoprotective effect on ischemic cardiomyocytes for cardiac regeneration due to these factors such as VEGF, HGF, FGF, IGF-1, and TB4 [35]. In addition, these following growth factors have been linked to the proliferative and regenerative effects: HGF, VEGF, SDF-1, KGF, FGF, PGF, MCP-1, and IGF-1 [36]. Furthermore, MSC anti-inflammatory effects are evidenced by the production of anti-inflammatory cytokines (IL-10 and TSG-6) and reduction of proinflammatory factors (IL-1a, IL-6, IL17, IFN $\gamma$, GCSF, GM-CSF, MIP2a, and MCP-1) [37]. MSCs are also found to secrete VEGF-A, which is responsible for angiogenesis, and Ang1/Ang2, which have roles in neovessel maturation, and altogether these factors contribute to wound healing [37].

Recently, MSCs have become an attractive target of secretome profiling studies aiming to discover proteins regulating cell survival, proliferation, differentiation, or inflammatory response. The MSC secretome is a complex sample, largely due to the difficulties in its collection and preparation for further analysis and functional studies [28]. The MSC secretome presents several beneficial properties, for example, low immunogenicity, stability during extended storage, and their encapsulation basically protects their contents from cellular degradation [3]. To promote a better biological response from MSCs, preconditioning of MSCs will open up the opportunities to achieve a tailor-made secretome profile.

\section{MSC-Derived Exosomes}

Trophic factors released by MSCs in soluble or vesiclebound forms are referred to collectively as the secretome or sheddome, respectively. This section of the review will focus on the MSC sheddome, its characteristics, potential clinical applications, and outcomes from recent clinical trials attempting to exploit their functionality. The contents of the extracellular vesicles (EVs), referred to as their "cargo," uncovered using mass spectrometry, next generation sequencing, and lipid profiling, have allowed us to infer their potential function $[38,39]$. Emerging evidence indicates that EV cargo comprised molecules with diverse biological properties, including lipids (ie, cholesterol, sphingomyelin, and hexosylcermides), proteins (both endosome-associated proteins, tetraspanins, and lipid raft-associated proteins, as well as discrete protein cargo), RNA subtypes (ie, mRNA, miRNA, tRNA, rRNA, siRNA, and IncRNA), and DNA subtypes (ie, mtDNA, ssDNA, and dsDNA) [40-42]. Given the bioactive nature of their cargo and likelihood that EVs shed by MSCs are reflective of their cells of origin, it is hardly surprising that the therapeutic potential of MSC-EVs is a subject of active

Table 1. Paracrine Factors Derived from Human Mesenchymal Stem Cell and Their Effects

\begin{tabular}{|c|c|c|c|}
\hline Cell type & Paracrine factors & Paracrine action & Reference \\
\hline STRO $^{+}{ }^{+}$BMMSC & $\begin{array}{l}\text { Conditioned media } \\
\text { containing CXCL12, } \\
\text { MCP-1, VEGF, } \\
\text { HGF, IL-6, IL-8 }\end{array}$ & $\begin{array}{l}\text { Increase proliferation of cardiac muscle cells } \\
\text { Increase endothelial tube formation }\end{array}$ & [97] \\
\hline $\begin{array}{l}\text { BMMSC, } \\
\text { adipose MSC, } \\
\text { dermal tissue MSC }\end{array}$ & $\begin{array}{l}\text { GRO, IL-6, IL-8, MCP- } \\
\text { 1, RANTES, SDF-1, } \\
\text { TNF } \alpha \text {, angiogenin, } \\
\text { VEGF-A, VEGF-D, } \\
\text { leptin }\end{array}$ & $\begin{array}{l}\text { Promote proliferation and migration of HMEC } \\
\text { in vitro } \\
\text { Promote angiogenesis of HMEC in vitro using } \\
\text { tube formation assay }\end{array}$ & [2] \\
\hline BMMSC & $\begin{array}{l}\text { miRNA-containing } \\
\text { exosomes }\end{array}$ & $\begin{array}{l}\text { Inhibit macrophage activation by suppressing } \\
\text { Toll-like receptor signaling }\end{array}$ & [98] \\
\hline BMMSC & Exosomes & Facilitate bone repair in a mouse model & [27] \\
\hline Akt-MSC & Conditioned media & $\begin{array}{l}\text { Protection of ischemic myocardium in vivo after } \\
\text { acute infarction }\end{array}$ & [99] \\
\hline Umbilical cord MSC & Exosomes & Reduce liver fibrosis in a mouse model & [36] \\
\hline BMMSC & Exosomes & Improve diabetes-induced cognitive impairment & [100] \\
\hline BMMSC & Angiopoietin-1, KGF & $\begin{array}{l}\text { Restore epithelial permeability in alveolar } \\
\text { epithelial cells }\end{array}$ & [101] \\
\hline Adipose MSC & Conditioned media & Increase adipogenic differentiation & [64] \\
\hline $\begin{array}{l}\text { Adipose and umbilical } \\
\text { cord MSC }\end{array}$ & Conditioned media & $\begin{array}{l}\text { Inhibit proliferation and induce differentiation } \\
\text { of glioma cells }\end{array}$ & [102] \\
\hline BMMSC & Conditioned media & $\begin{array}{l}\text { Induce migration and proliferation of renal } \\
\text { epithelial cells and reduce cisplatin-induced } \\
\text { proximal tubule cell death }\end{array}$ & [103] \\
\hline BMMSC & Conditioned media & $\begin{array}{l}\text { Promote endothelial cell and smooth muscle cell } \\
\text { proliferation and migration }\end{array}$ & [104] \\
\hline
\end{tabular}

BMMSC, bone marrow-derived mesenchymal stem cell; CXCL, chemokine C-X-C motif ligand, MCP, monocyte chemoattractant protein; VEGF, vascular endothelial growth factor; HGF, hepatocyte growth factor; IL, interleukin; GRO, growth-related oncogene; RANTES, regulated on activation normal T cell expressed and secreted; SDF, stromal cell-derived factor, TNF, tumor necrosis factor; HMEC, human dermal microvascular endothelial cells. 
research. EVs are generally separated into two major subpopulations, namely exosomes and microvesicles (MVs).

Exosomes are smaller with a size range of $40-120 \mathrm{~nm}$ and originate from the endosomal compartment where intraluminal vesicles within multivesicular bodies are released by exocytosis. In contrast, MVs are larger $(\sim 200-1,000 \mathrm{~nm})$ and bud directly from the plasma membrane. These EVs can be purified through a number of means, including size-based separation such as differential ultracentrifugation and ultrafiltration, density-based separation such as sucrose and OptiPrep ${ }^{\mathrm{TM}}$ gradients, as well as immunoaffinity and polyethylene glycol precipitation of the EVs $[43,44]$. It should be noted, however, that none of these methods is able to reliably separate EV subgroups. Indeed, this is a major technical challenge for the EV field at this moment. Researchers should therefore consider inherent biases in each purification strategy and this has the potential to influence biological functions and biochemical properties of the isolated EVs.

The minimal requirements for the definition of EVs are detailed in a position article published by the International Society for Extracellular Vesicles [45]. The authors suggest that each EV preparation must quantify proteins that should be enriched in EVs, given the absence of exosome-specific markers. Indeed, investigators are recommended to report the amount of three or more proteins known to be enriched in EVs in, at least, a semiquantitative manner [45]. These are generally thought to be transmembrane proteins or cytosolic proteins with membrane binding capacity. Furthermore, when comparing the relative abundance of these proteins to that of the secreting cells, such as in the case of MSC-derived EVs, it is important to also measure the relative abundance of intracellular proteins that are not expected to be enriched in EVs, such as those associated with the endoplasmic reticulum and mitochondria. The relative abundance or absence of these proteins will also inform on the extent of coisolation of EVs from different cellular compartments.

A recent in-depth proteomic analysis of MSC-derived EVs has shown that MSCs are able to package as much as one-third of their protein content within EVs [39]. The mechanisms of action of MSC-derived EVs are, of course, not limited to their proteomic cargo and their release into target cells. MSCs have also been observed donating cytoplasmic material to other cells using nanotubules and EVs [46], thereby supporting the notion that MSCs may utilize EVs in their intercellular communication. Tunneling nanotubules and EVs have been observed in intercellular communications between MSCs and human peripheral T cells where there was evidence of bidirectional transfer of cellular material between the cells [47]. Interestingly, the tunneling nanotubules were exclusively produced by the $\mathrm{T}$ cells. This novel mechanism of cellular communication may be the basis of the immunomodulatory actions of MSCs.

The subsequent sections will discuss the preclinical assessments of MSC-derived EVs in a variety of disease settings.

\section{Bone and cartilage damage}

The therapeutic potential of MSCs in orthopedic applications has been thoroughly explored over the past decade. The clinical translation of this research has progressed to com- mercial off-the-shelf MSC products such as in the case of Orthocell (Perth, Western Australia). In an attempt to evaluate the potential for MSC-EVs in this setting, MSC-EVs were isolated from MSC-conditioned media and tested in a femur fracture model of $\mathrm{CD}^{-1-}$ mice, which are known to produce reduced levels of exosomes [48]. The authors observed a significant reduction in bone union rate in the $\mathrm{CD}^{-/-}$ mice compared to wild-type mice, and this is attributed to retardation of callus formation. This was rescued by the injection of MSC-EVs, but not by EV-depleted MSCconditioned media. When levels of fracture resolution proteins were measured, the levels of MCP-1, MCP-3, and SDF-1 were lower in MSC-EVs compared with MSC-conditioned media and EV-depleted MSC-conditioned media. This led to the postulation that bone repair may be, in part, mediated by other exosome components, such as miRNAs [48].

At the same niche, MSC-EVs have recently been shown to rescue radiation damage to $\mathrm{BM}$ hematopoietic stem cells [49]. BM stem cell engraftment was significantly enhanced by exposure to MSC-EVs at 3 weeks to 9 months after transplant, and further confirmed by secondary engraftment. Intravenous delivery of MSC-EVs to mice exposed to 500 cGy resulted in a partial recovery of peripheral blood counts and restoration of the engraftment of BM. When the murine hematopoietic cell line FDC-P1 was exposed to the same level of irradiation, the authors observed a reversal of growth inhibition, DNA damage, and apoptosis on exposure to MSC-EVs. EVs from human embryonic MSCs have also been shown to promote cartilage regeneration in an immunocompetent rat osteochondral defect mode, where MSCEVs accelerated neotissue filling and enhanced matrix synthesis of type II collagen and sulfated glycosaminoglycan. At the end of a 12 -week study, rats that received MSC-EVs displayed complete restoration of cartilage and subchondral bone, complete bonding to adjacent cartilage, and extracellular matrix (ECM) deposition resembling that of age-matched controls. In contrast, only fibrous repair was observed in contralateral control defects treated with the vehicle [50].

\section{Cardiovascular disease}

The therapeutic efficacy of MSC-EVs has been reported in a mouse model of myocardial ischemia-reperfusion where the infarct size was nearly halved and a significant improvement in cardiomyocyte survival was observed [51]. It is worth noting that the antiapoptotic effect of MSC-EVs is closely associated with miR-21-mediated targeting of methyl CpG-binding protein 2 [52]. Furthermore, genetic modification of MSCs with GATA-4 has been reported to increase EV efficacy for cardiac repair with increased cardiomyocyte survival, reduced apoptosis, and enhanced cardiac contractile function in mice subjected to myocardial infarction [53]. The antiapoptotic effect of GATA-4 MSCEVs was attributed to the enrichment of miR-19a that targets phosphatase and tensin homologue (PTEN), leading to activation of Akt and Erk signaling pathways.

\section{Tissue fibrosis}

The therapeutic potential of MSCs in fibrotic conditions is currently being investigated in over 50 clinical trials (out of 
a total of 688 clinical trials involving MSCs) around the world (www.clinicaltrials.gov); however, there are currently limited reports on the efficacy of MSC-EVs in models of tissue fibrosis. In the case of renal fibrosis, MSC-EVs enriched in miR-let7c have been reported to attenuate kidney damage concurrently with a significant reduction in the expression of collagen IV $\alpha 1$, metalloproteinase-9, TGF $\beta 1$, and TGF $\beta$ R1 following unilateral ureteral obstruction [54]. Similar findings were reported in a mouse model of silicainduced lung fibrosis where intravenously delivered MSCEVs reduced deposition of collagen in the lungs. In addition, pulmonary inflammatory infiltrates were reduced and numbers of foamy macrophages were noticeably reduced in the lungs of animals that received the MSC-EVs [55]. In a recent assessment of the potential of MSC-EVs for liver fibrosis, MSCs isolated from the chorionic plate were found to produce EVs that were highly enriched with miR-125b [56]. This miRNA was shown by the authors to target sonic hedgehog signaling, which is elevated in liver fibrosis. Furthermore, the MSC-EVs were found to reverse inhibition of liver progenitor cell expansion and stellate cell activation [56]. This finding supports an earlier report showing that MSCs from the umbilical cord tissue could reduce surface fibrous capsules in a carbon tetrachloride model of liver fibrosis [57]. This earlier study reported similar findings, in that MSC-EVs reduced serum levels of aspartate aminotransferase, reduced liver collagen content, TGF $\beta 1$, and phosphorylated Smad2, along with evidence of reduced stellate cell activation.

\section{Mechanisms Controlling Paracrine Factor Production and Release}

An area of active interest is how paracrine factor production and release are modulated. There are two aspects to this; first, how information is received by the cell to alter expression of paracrine factors and second, the mechanisms that control the subsequent release of proteins or exosomes from the cell. MSCs can be stimulated to release proteins in response to hypoxia or culture in a serum-free medium. One of the methods that cells communicate and exchange cellular information is by secretion of these factors (soluble proteins, exosomes, and MVs), which in turn induces phenotypic and functional changes in the recipient cells. In the traditional secretory pathway, proteins are sorted in the Golgi apparatus, transported to the plasma membrane, and released by fusion with the plasma membrane [58].

The mechanisms that control biogenesis and composition of exosome cargo are still not well understood. One proposed molecular mechanism is through the Endosomal Sorting Complex Required for Transport (ESCRT), which could play a role in binding and sorting of ubiquitinylated proteins into exosomes [58]. Alix has been shown to participate in endocytic membrane trafficking and cytoskeletal remodeling [59]. Baietti et al. reported that biogenesis of exosomes is controlled by syntenin (cytosolic adaptor), which connects syndecans with Alix, and these assemblies support endosomal membrane budding [60]. Interaction of Alix with the ESCRT is mainly associated with the accumulation of the luminal cargo of the exosomes.

The mechanisms involved in the release of exosomes include the cytoskeleton (actin and microtubules), molecular motors (kinesins and myosins), small GTPases, and the fusion machinery (SNAREs and tethering factors) [40]. Exosomes are released by p53-regulated exocytosis, and its biogenesis depends on cytoskeleton activation but $\mathrm{Ca}^{2+}$ independent [61]. The challenges now are to define what specific bioactive factors are contained in the exosomes and elucidate the physiological importance of this exosome transfer. The cargo of the exosomes could potentially be manipulated to achieve specific and efficient delivery of bioactive factors to selected target cells.

\section{Sensing of external cues and transduction into the cell}

In terms of sensing information that guides the production of different paracrine factors, the mechanisms of a wide range of different soluble factors have been wellcharacterized $[4,35,37]$. An often overlooked source of information for cells comes from matrix-derived cues, and mechanotransduction is the major process by which cells detect and subsequently respond to extracellular stimuli. In this process, cells detect outside-in signals, relay them through the cytoplasmic compartment, and elicit an alteration to gene/protein expression. This change in expression profile can then further alter the extracellular environment through an inside-out signaling mechanism. This signal feedback loop utilizes multiple cellular components situated across both extracellular and nuclear compartments (Fig. 2).

The primary means by which cells receive mechanical information is through integrin signaling. Specific dimers of alpha and beta integrins bind to peptide motifs within ECM proteins and facilitate cell adhesion, which in turn leads to the formation of focal adhesion complexes (FACs). This multiprotein complex acts as the primary site from which cells assess and subsequently relay mechanical information through the cytoplasm. Importantly, they provide a physical link between the integrin-ECM interactions outside the cell and to the actin cytoskeleton within the cell. One mechanism by which FACs transmit mechanical cues from the ECM to the cytoplasmic compartment is through the exposure of tension-sensitive cryptic binding sites. For example, following the application of tension forces, Talin (a FAC protein situated across the cytoplasmic face) was demonstrated to undergo conformational changes, which in turn exposed previously buried vinculin binding sites [62]. Similarly, force-induced conformational changes to FAC proteins may also expose sites for modification, allowing for the recruitment of new interactions [63]. For example, through the application of mechanical stretching, conformational changes induced in p130CAS exposed several tyrosines, which could be phosphorylated by Src, in turn allowing the force-dependent activation of the small GTPase RAP1 [64]. It is therefore evident that changes to the FAC composition and structure through altered integrin specificity of perturbation of tension (ie, through substrateinduced cell spreading), thus, allow the transmission of varying mechanical information [65].

The regulation of cytoskeletal tension in response to environmental cues is heavily influenced by RhoA and ROCK activity across FACs [66]. RhoA acts to regulate focal adhesion formation and actin contractility through downstream phosphorylation cascades, able to regulate myosin contractility and 


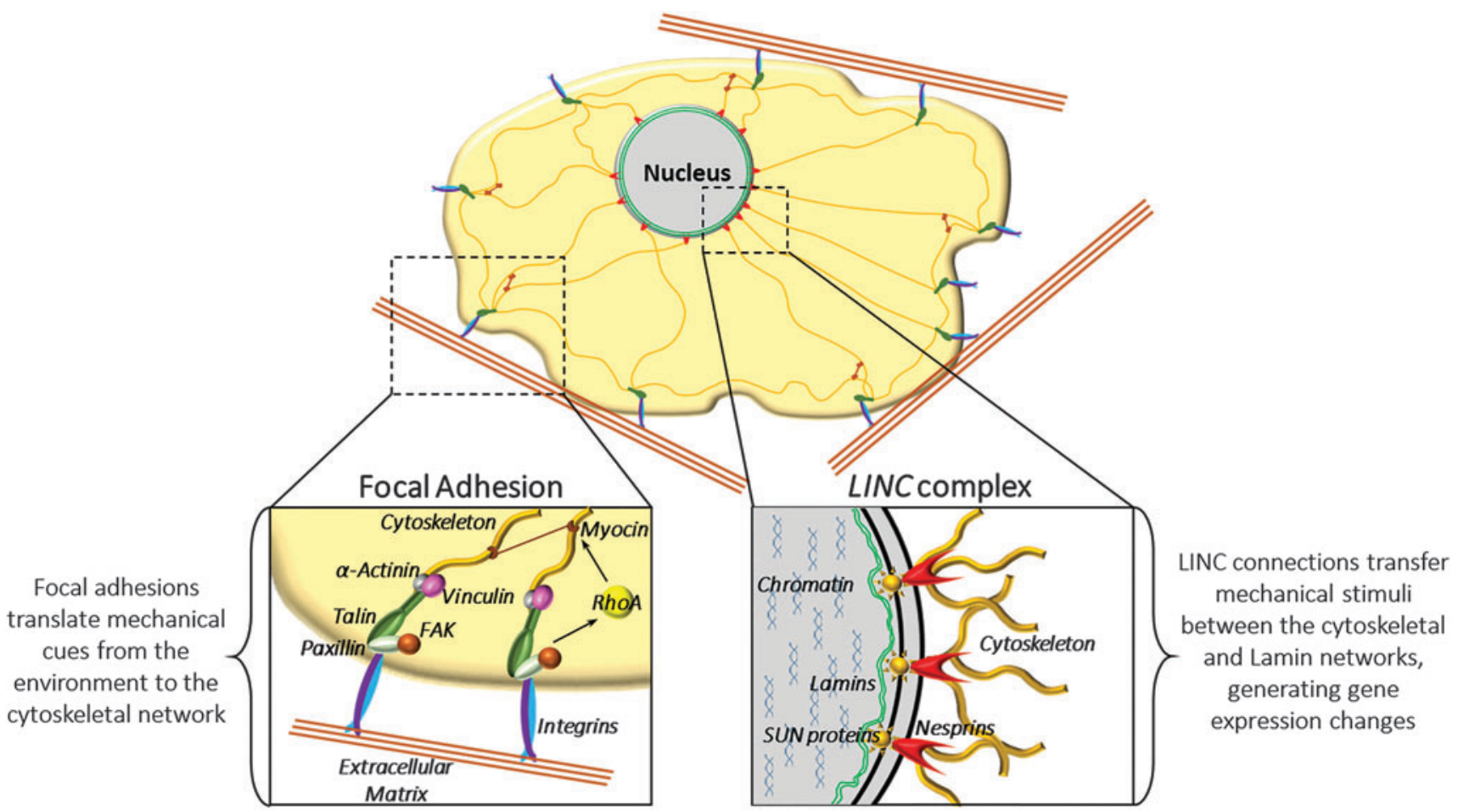

FIG. 2. Cellular components involved in mechanotransduction. Focal adhesion sites situated across the cell periphery transmit tension forces across the cytoskeletal elements (actin, microtubule, and intermediate filament networks) to the NE. These forces are further transferred across the NE through SUN-KASH interactions associated with the LINC complex. Once within the nuclear compartment, these mechanical cues detected at the cell periphery are translated to biochemical and biological responses, such as changes in gene and protein expression, and ultimately paracrine signaling. KASH, Klarsicht ANC-1 and SYNE-Nesprin-1/-2 homology; LINC, linker of nucleoskeleton and cytoskeleton; NE, nuclear envelope. Color images available online at www.liebertpub.com/scd

in turn MSC lineage $[67,68]$. Of particular interest in this context, the RhoA activity in MSCs was recently shown to alter the secretion of matrix metalloproteinase 3 (MMP3). This cleaved CTGF, resulting in VEGF release and provides a clear example of how modulation of mechanical signaling can lead to an altered secretion of a protein and subsequent changes to the extracellular environment, which then provide inductive signals to locally bound cells [69].

\section{Force transmission from the cytoplasm to the nucleus}

To convert information from mechanical signaling cascades into changes in gene expression and functional outputs, it is necessary to transmit information on physical cues and forces into the nucleus. However, the processes by which these mechanical cues are conveyed across the nuclear envelope (NE) are still unknown. It has been suggested that the nucleus of a cell, similar to the cytoplasmic compartment, is under continuous tension [70,71] and alterations to this tension may elicit changes to chromatin structure and gene expression. In recent years, the linker of nucleoskeleton and cytoskeleton (LINC) complex has been highlighted as a key structure through which mechanical stimuli may be directly transferred across the nuclear surface.

Comprising outer nuclear membrane, Klarsicht ANC-1 and SYNE-Nesprin-1/-2 homology (KASH) proteins, and inner nuclear membrane SUN proteins, the LINC complex provides a physical bridge between nuclear and cytoplasmic compartments. The formation of this two-membrane adhesive assembly enables the transmission of force across the $\mathrm{NE}$, providing function in maintaining centrosome-nuclear interactions, nuclear architecture, signal transduction, DNA repair, and chromosome migration [72]. It can therefore be suggested that the LINC complex must be a dynamic protein network of highly ordered interactions, allowing the transmission of multiple signal transductions from a variety of cytoskeletal components to the nuclear interior. In recent work, it was shown that maintaining LINC connections is the key to detection and transmission of mechanical cues across the NE, and in turn regulating gene expression [73]. For example, in Lamin A/C- and Emerin-deficient mouse embryonic fibroblasts, the expression of lex-1, EGR-1 [74], and MKL-1 [75] is impaired in response to cyclic strain, resulting in the loss of signal translocation to the nuclear compartment. With further investigations proposing EGR-1 as a mediating transcription factor in response to TGF $\beta 2$ signaling [76], it can therefore be concluded that LINC connections are vital to the maintenance of signal transduction from the ECM and to elicit changes in gene regulation.

Together, these mechanisms provide the machinery by which extracellular stimuli can be coupled to intracellular compartments and ultimately transmitted into the nucleus to exert changes in gene expression. Although it is clear that the MSC secretome and exosome composition change in 
response to physical extracellular cues, this is currently a largely untouched area of research. Future attempts to couple the observed MSC paracrine behaviors with these mechanotransductive mechanisms will provide important insights into how these factors are linked.

\section{Effect of MSC Origin and Potency on Paracrine Activity}

The most critical factor when harnessing MSC paracrine activity for therapeutic purposes is the quality and potency of the cells themselves. With similarities and differences between MSCs derived from different tissue sources, their applicability to varying therapeutic applications is a topic of ongoing debate and so, inevitably, MSCs from different tissue sources have been shown to have both varying secretory profiles [77] and distinct exosome compositions [42].

The secretome of various MSC populations has been profiled, with studies generally showing that MSCs secrete a mixture of ECM constituents, immunomodulatory factors, and a complex cocktail of growth factors and cytokines, although there are variations in the precise composition reported between publications [26,78]. Systematic studies that specifically compare MSCs from different tissue sources have confirmed that the paracrine activity of MSCs is dependent upon origin. One study compared BM, adipose (AD), and Wharton's jelly MSCs and found that Wharton's jelly-derived MSCs secreted the greatest amount of immunomodulatory factors, such as IL-6, -7, and -10, as well as PDGF-AA and TGF $\beta 2$, while AD-MSCs produced significantly more ECM proteins and enzymes, for example, collagens 1 and 2 and MMPs [79]. Pires et al. also saw differences in the production of neuroregulatory factors between BM-, AD-, and umbilical cord-derived MSC populations [77].

The most significant difference has been shown in the therapeutic potential of fetally derived versus adult MSCs. Factors produced by fetal MSCs have shown potential use as both therapeutic agents in their own right, but also as paracrine modulators. Factors released by fetal MSCs were able to reduce replicative senescence in adult MSCs and had more potent pro-osteogenic effects than adult MSC secretome when injected into a rat distraction osteogenesis model [80]. It is well characterized that both the age and tissue source of MSCs provide unique cellular phenotypes, including differential expression of inhibitory kappa B kinase (IкB), mitogen-activated protein kinase, nuclear factorkappa B (NF-кB), CD151, LAMP1, and LAMP2 [81-83]. Although our knowledge of age- and source-related changes to MSCs is expanding, our understanding of these effects on the MSC secretome is currently limited. Recent investigations are beginning to shed light on this area, suggesting alterations in exosome functionality with increasing MSC age. In a recent study, MSC exosomes were shown to express functional respiratory complexes I, IV, and V, which may act to consume oxygen and promote aerobic ATP synthesis restoration in damaged cells. However, in a comparison between exosomes isolated from culture media of umbilical cord MSCs of $\geq 37$-week-old newborns (ie, term infants) and 28-30-week-old newborns (ie, preterm infants), ATP synthesis was only detectible in exosomes from term newborns, suggestive of a specific mechanism that is not completed at an early gestational age [84]. These findings therefore suggest that MSC exosome signaling may contain a further layer of signaling complexity based on cellular age.

The differentiation status of MSCs has also been shown to influence their paracrine activity with distinct changes occurring during osteogenic, chondrogenic, and adipogenic lineage commitment. As would be anticipated, many of these changes reflect the change in function of these cells. For example, Arufe et al. [85] showed that the proteins secreted by MSCs from umbilical cord stroma changed as they underwent chondrogenic differentiation and further determined that, of the 342 different proteins identified, $17 \%$ were factors already linked to chondrogenesis (eg, MMPs and ECM proteins).

Extending on this principle, a conditioned medium from both osteogenic [86] and adipogenic [87] MSC cultures has been shown to enhance these respective differentiation processes in recipient MSC cultures. This not only suggests that paracrine signaling mechanisms play an important role during typical MSC differentiation but also that modulating such signaling is a strategy that could be used to enhance the differentiation process. Clearly, the source of the conditioned medium is critical, as demonstrated by the fact that clear differences exist between the pro-osteogenic effect of conditioned medium collected from either osteogenic or undifferentiated MSC cultures [88].

\section{Microenvironmental Effects on MSC Paracrine Signaling}

We propose that the environment surrounding the MSCs is of critical importance to direct the paracrine activity. It is logical that the optimum therapeutic response will only be generated when the cells are producing the necessary factors to mediate the desired effect. To date, attempts to monitor or even control this have been somewhat limited. However, it is clear that the status of the MSC population has a huge impact upon the factors produced by the cell and their activity (Table 2). The cellular microenvironment, which we typically hope to approximate during in vitro culture, provides information to the cell through soluble factors, physical factors (such as ECM composition, geometry, and mechanical properties), and oxygen tension. In this study, we evaluate the evidence that the cellular microenvironment contributes to the paracrine activity of MSC populations and should be considered when culturing MSCs whose therapeutic efficacy will be mediated by paracrine signaling.

\section{Soluble signaling factors}

Many soluble factors are sensed by MSCs and subsequently alter their paracrine activities. For example, Ren et al. showed that the ability of MSCs to suppress T cell proliferation required the MSCs to receive soluble factors released by activated $\mathrm{T}$ cells, and in the absence of these factors, the MSCs had no impact on $\mathrm{T}$ cell proliferation [89]. The mechanism for this effect was determined to be mediated by $\mathrm{TNF} \alpha$, IFN $\gamma$, and IL- $1 \alpha / 1 \beta$ acting upon the MSCs and induced them to produce large amounts of CXCL9 and CXCL10. In a separate study, activation of MSCs with $\mathrm{TNF} \alpha$ and IFN $\gamma$ was also shown to increase production of IL-6, HGF, VEGF, and TGF $\beta$ and promote bone formation [90]. 
Table 2. Summary of Mesenchymal Stem Cell Paracrine Factors Showing Sensitivity to Microenvironmental Conditions

\begin{tabular}{|c|c|c|}
\hline Microenvironmental cue & Paracrine factors & Reference \\
\hline \multicolumn{3}{|l|}{ Soluble signaling factors } \\
\hline $\mathrm{IFN} \gamma, \mathrm{TNF} \alpha, \mathrm{IL}-1 \alpha, \mathrm{IL}-1 \beta$ & CXCL9, CXCL10 & [66] \\
\hline $\mathrm{IFN} \gamma, \mathrm{TNF} \alpha$ & IL-6, HGF, VEGF, TGF $\beta$ & {$[67]$} \\
\hline TGF $\beta$ & $\begin{array}{l}\text { PIGF, IGFBP-3, LIF, OSM, IL-4, IL-7, IL-13, CXCL9, } \\
\text { CCL26, osteopontin }\end{array}$ & {$[68,90]$} \\
\hline Lipopolysaccharide & miRNA let-7b & {$[70]$} \\
\hline \multicolumn{3}{|l|}{ Oxygen tension } \\
\hline Hypoxia $\left(5 \% \mathrm{O}_{2}\right)$ & $\begin{array}{l}\text { thymosin-b, EF-2, PEDF, IGF-2, semaphorin-7A, MIF, HSP70, } \\
\text { and moesin }\end{array}$ & [73] \\
\hline Near anoxia $\left(0.1 \% \mathrm{O}_{2}\right)$ & VEGF-A, VEGF-C, IL-8, RANTES, MCP-1 & [74] \\
\hline Hypoxic preconditioning & GM-CSF, VEGF, IL-6, and IGF-1 & [75] \\
\hline Ischemic preconditioning & $\begin{array}{l}\text { Exosomes enriched in miR-21, miR-22, miR-199a-3p, } \\
\text { miR-210, miR-24 }\end{array}$ & [31] \\
\hline Ischemic preconditioning & Exosomes & [77] \\
\hline \multicolumn{3}{|l|}{ 3D cell culture } \\
\hline 3D spheroids & PGE2 & [78] \\
\hline 3D spheroids & TSG-6, STC-1, LIF & [79] \\
\hline 3D spheroids & IL-24 & [80] \\
\hline \multicolumn{3}{|l|}{ Matrix composition } \\
\hline RGD-modified alginate hydrogels & VEGF & {$[105]$} \\
\hline Collagen vs. laminin & VEGF, IL-6, GM-CSF, TGF $\beta 1$, TNF $\alpha$ & {$[82]$} \\
\hline \multicolumn{3}{|l|}{ Matrix mechanical properties } \\
\hline Matrix stiffness & VEGF, IGF, EGF, IL-6 and IL-8 & [89] \\
\hline \multicolumn{3}{|l|}{ Mechanical stimulation } \\
\hline Multiaxial tension & BLC, VEGF, MDC, MIP3 $\alpha$, LAP, MMP13 & [91] \\
\hline Mechanical load & MMP2, TGF $\beta$, FGF & {$[90]$} \\
\hline
\end{tabular}

TGF $\beta$ is also widely reported to alter MSC function through their secretory activities. In a study by Rodriguez et al., MSCs treated with TGF $\beta 1$ increased their production of a range of factors involved in MSC immunosuppression and bone remodeling, including PIGF, IGFBP-3, LIF, OSM, IL-4, IL-7, IL-13, CXCL9, CCL26, and osteopontin [91]. There is also an autoregulatory loop in which the response of MSCs to TGF $\beta 1$ is to upregulate their production of TGF $\beta 1$ and 2 [92].

Although much less is currently known about the effect of soluble signaling mechanisms on MSC exosome signaling, it has been shown that treating MSCs with lipopolysaccharide modulates the abundance of miR-let-7b in MSCderived exosomes, which in turn enhances wound healing and decreases inflammation by signaling to macrophages [93]. This provides proof-of-concept that soluble factors can also modulate the composition and activity of MSC-derived exosomes.

\section{Oxygen tension}

In vivo, the $\mathrm{O}_{2}$ tension of the tissues is typically far lower than the $20 \% \mathrm{O}_{2}$ present in our atmosphere, with models predicting that MSCs are adapted to $\mathrm{O}_{2}$ tensions from $1 \%$ to $7 \%$ [94]. Consistent with this, several studies have demon- strated that MSCs cultured under low $\mathrm{O}_{2}$ conditions better retain their proliferative capacity, surface antigen expression profile, expression of "stemness" genes, and differentiation potential in comparison with those cultured in atmospheric $\mathrm{O}_{2}$ [95]. Increasingly, paracrine signaling is also emerging as a factor that is heavily influenced by $\mathrm{O}_{2}$ tension.

Under hypoxic conditions, Wharton's jelly-derived MSCs secreted increased levels of thymosin-b, EF-2, PEDF, IGF2, semaphorin-7A, MIF, HSP70, and moesin [96]. Various studies have also indicated functional differences in response to changing paracrine signaling; Paquet et al. showed that the conditioned medium collected from MSCs cultured in $0.1 \% \mathrm{O}_{2}$ had greater chemotactic and proangiogenic properties than normoxic conditioned medium, as well as a reduced inflammatory mediator content [97]. Such changes have also been proven to alter the regenerative effect of the cells. When using MSCs to remodel salivary glands after radiation treatment, hypoxic preconditioning of the MSCs improved the therapeutic response and this was associated with an increase in the production of GM-CSF, VEGF, IL-6, and IGF-1 [98]. Conversely, hypoxia-induced changes in the secretome impaired cardiac repair by MSCs, although in this case, the specific factors were unknown [99].

As with other stimuli, far less is currently known regarding exosomes and $\mathrm{O}_{2}$ tension than is known about 
protein secretion. However, it has been shown that exosomes derived from MSCs cultured under hypoxia provided better protection in a mouse acute lung injury model than those derived from normoxic MSCs [100]. Ischemic preconditioning was also shown to enrich for miR-21, miR-22, miR-199a-3p, miR-210, and miR-24 in MSC-EVs, and administration of the EVs reduced cardiac fibrosis and apoptosis compared to control EVs [52]. Anderson et al. further demonstrated that priming of MSCs using a combination of serum starvation and hypoxia $\left(1 \% \mathrm{O}_{2}\right)$ resulted in EVs that were enriched in PDGF, epidermal growth factor (EGF), and NF- $\kappa \mathrm{B}$ signaling pathways. Enrichment of this specific EV cargo was then correlated to their improved proangiogenic potential [39]. As we gain a better understanding of MSC exosome composition and function, it is likely that other factors will also emerge.

\section{Substrate and ECM cues}

The earliest indications that MSC paracrine signaling depends upon their physical microenvironment come from studies that adopted spheroidal aggregates (akin to embryoid bodies) as a simple scalable system for 3D MSC culture. Cell spheroids change the microenvironment to provide cells with 3D context and induce changes to cell shape and polarity, while encouraging cell-cell interactions.

The Prockop group showed that MSCs cultured as 3D spheroids have anti-inflammatory properties far superior to those of 2D MSC cultures. The conditioned medium from MSC spheroids inhibited macrophage proliferation and altered the bias between M1 and M2 phenotypes [101]. Further investigation revealed that this was due to an increased secretion of PGE2, which subsequently decreased production of the proinflammatory TNF $\alpha$, CXCL2, IL-6, IL-12, and IL-23 by the macrophage population [102]. In another study, 3D spheroid culture induced the production of IL-24 by MSCs. This factor has potent anticancer properties and consequently, the conditioned medium from $3 \mathrm{D}$, but not $2 \mathrm{D}$, MSCs reduced the viability of a number of cancer cell lines, while leaving their noncancerous counterparts unaffected [103].

Ho et al. [104] compared MSC spheroids encapsulated within alginate hydrogels to dispersed MSCs. Both systems provide 3D context, but differ in whether the cells are primarily in contact with the matrix or other cells. Their results highlighted two interesting phenomena; first, VEGF production was greater from the MSC spheroids than single cells, which might indicate that changes in $\mathrm{O}_{2}$ resulted in an altered angiogenesis. Second, the levels of VEGF were more than twice as high when adhesive RGD peptides were incorporated into the hydrogel matrix. This suggests that integrin binding and related signaling feeds into the MSC secretory activity. There is certainly much more to be elucidated as to the role of integrin binding in paracrine activity, but data from De Lisio et al. provide a tantalizing glimpse by showing that the expression of key paracrine factors, such as VEGF, IL-6, GM-CSF, TGF $\beta 1$, and TNF $\alpha$, were altered between MSCs cultured on collagen or laminin, in which different integrins will mediate cell attachment [105].

In addition to biochemical information, the ECM (or materials in which MSCs are encapsulated) provides information to cells based on the mechanical properties, for example, substrate stiffness, time-dependent deformation [106108], ligand spatial context [109], topography [110,111], and much more. All of these factors are known to play important roles regulating MSC proliferation and differentiation. Of these cues, we already know that substrate stiffness (elasticity) can influence the paracrine activity. When MSCs were cultured on polyacrylamide hydrogels of varying stiffness, VEGF and IGF were upregulated with increasing modulus, while EGF, IL-6, and IL-8 showed biphasic secretory profiles [112]. This indicates that the mechanical properties of the MSC microenvironment will likely require optimization when specific paracrine factors are desired.

\section{Mechanical stimulation}

Aside from the soluble and matrix-derived cues that MSCs receive, cells in vivo are also subject to a variety of mechanical forces such as fluid shear stress, tension, and compression, which also provide context to the cells and can drive MSC behavior. Furthermore, it is becoming increasingly evident that mechanical stimulation can alter the MSC paracrine activity. In a recent study, conditioned media from mechanically loaded MSCs promoted angiogenesis within human dermal microvascular endothelial cells (HMECs) [113]. Further screening of the secretome between control and mechanically loaded MSCs attributed these findings to significantly increased levels in MMP2, TGF $\beta$, and FGF. As each of these factors has been linked to angiogenic fate determination, it was concluded that bioreactor-mediated mechanical loading was able to alter the MSC secretome to favor angiogenic differentiation.

Recent evidence now further suggests that the MSC secretome may also vary in response to different mechanotransduction events. Gardner et al. showed that upon chondrogenic induction through either TGF $\beta$ incorporation or multiaxial mechanical loading, the resulting secretome compositions were observed to include soluble factors such as VLC, VEGF, and MMP13 [114]. However, under closer inspection, differential expression profiles were also observed for Leptin, MDC, MIP3 $\alpha$, and LAP, aside gene expression alterations of four factors: angiopoietin 2, GRO $\alpha$, $M M P 13$, and osteoprotegerin. These data therefore suggest that both TGF $\beta$ and load-induced chondrogenic differentiation present differences to the secretome compositions as a result of differing mechanotransduction pathways.

Interestingly, studies that showed how physical stimuli affect the MSC paracrine activity also started to provide some hints as to how these paracrine effects may be mediated. For example, in addition to demonstrating that secretion of VEGF, IGF, EGF, IL-6, and IL-8 is dependent upon substrate stiffness, Abdeen et al. [112] showed that the effects could be inhibited by using micropatterned islands to restrict cell spreading and therefore limit the changes to cytoskeletal architecture that are typically associated with substrate stiffness. Micropatterning has also been used to specify the geometry of MSCs (eg, stars and flowers) and these also gave rise to differential expression of soluble factors such as Wnts [115]. Such studies provide the first important insights into the role that mechanotransduction can play in regulating MSC paracrine signaling, although much more is yet to be determined. 


\section{Future Perspective: Engineering MSC Paracrine Signaling for Tissue Regeneration}

Collectively, the findings surveyed in this review indicate that signals from the microenvironment have an important influence on MSC paracrine signaling. Secretion of proteins can clearly be modulated by a wide range of extracellular cues, from soluble factors and oxygen tension to matrixmediated physical and mechanical cues. The field of exosomes is relatively new and so, not surprisingly, there are fewer examples of altered exosome composition and activity in relation to the cellular microenvironment. However, there are indications that exosome signaling is sensitive to soluble factors and oxygen concentration and so, it is likely that details of how exosome signaling will change with regard to other environmental cues will emerge as the field grows.

Importantly, the evidence is mounting that future therapies, which rely upon MSC paracrine signaling, will need to be underpinned by systematic evaluation of which culture parameters are important in modulating paracrine factor composition and how this changes in response to different specific cues. Insights from mechanistic studies will also have a role to play in linking how and why differences in paracrine signaling might occur in response to different cues. Given this knowledge, it is clear that there are nu- merous future opportunities to optimize MSC paracrine activity by control of cellular microenvironmental conditions and bioengineering and biomaterials science will play a critical role in this process (Fig. 3).

One aspect of this will be the acknowledgement that culture environment needs to be optimized to harness MSC paracrine activities when designing large-scale manufacturing processes for MSC clinical production. There have already been significant moves toward chemically defined media that remove the batch-to-batch variability associated with fetal bovine serum (reviewed by Frith et al. [116]). Different defined media formulations are currently commercially available and have been shown to alter secretion of TGF $\beta$ and Ang1 [117], indicating that the choice of medium is important. The evidence to show that proteins and exosomes released by MSCs are affected by soluble factors indicates that it may also be possible to supplement culture media with specific factors to elicit a particular response. Separate to this, it will clearly be desirable to know the secreted protein and exosome composition when producing MSCs for therapeutic use by any particular culture method.

The literature surveyed in this study also suggests that any particular culture method will impact paracrine signaling through biomechanical information sensed by the cell regarding cues such as substrate viscoelasticity, topography,

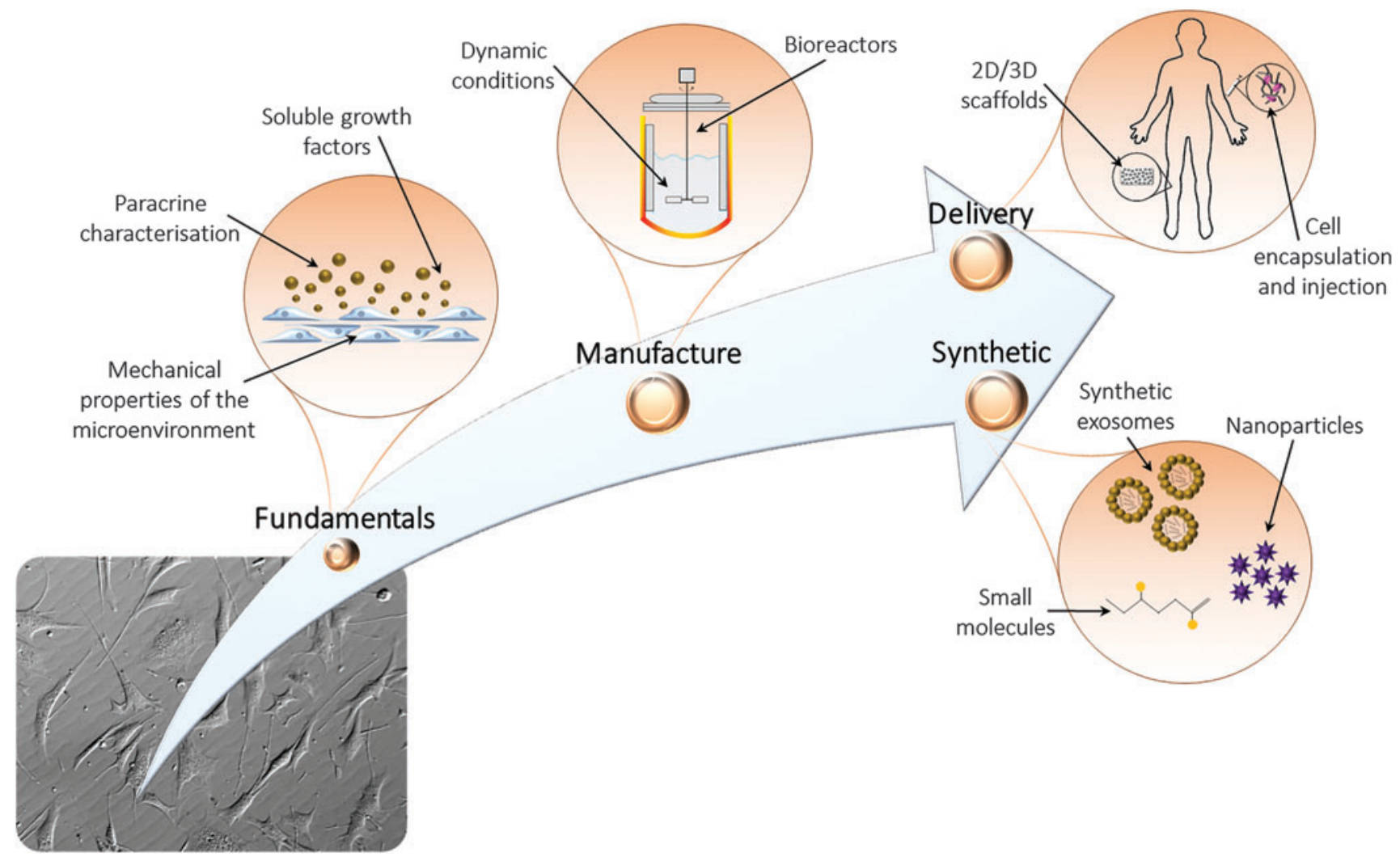

FIG. 3. Future strategies to harness MSC paracrine interactions for therapeutic applications. Our growing understanding of MSC fate determination in response to soluble, physical, and mechanical stimuli can be applied to determine environmental conditions, which favor select paracrine activities. Using this knowledge, it may be possible to incorporate bioreactors and novel culture techniques to increase the yield of primed MSCs or MSC-derived products for use in therapeutics. Finally, the development of synthetic biomaterials as a means of delivering specific paracrine factors may provide a key research area in the coming years, able to increase the efficacy of current MSC therapeutics. Color images available online at www.liebertpub.com/scd 
and ligand composition, and presentation. There is significant interest in the use of bioreactor technology for MSC expansion where many techniques exist, but a popular option is the concept of using dynamic suspension cultures of MSCs attached to beads to maximize surface area [118]. If systems like these are to be used, it will also be imperative to understand the influence of mechanical forces, such as fluid shear stress, on the MSC paracrine activity.

Aside from a focus on ensuring that the culture environment provides the best MSC state for clinical applications that rely upon secreted proteins or exosome signaling, harnessing microenvironmentally sensitive paracrine interactions may also provide effective means to improve the differentiation efficiency of MSC populations within tissueengineered constructs. It is already well established that factors released by MSCs can guide the fate of other cells in that population [86,87]. Harnessing these effects could provide additional means with which to help drive MSC fate within biomaterial constructs.

Moving beyond the general premise that microenvironmental conditions should be optimized, it is not beyond reason to imagine a situation where knowledge of how the microenvironment modulates the MSC paracrine activity is used to intelligently design in vitro culture environments, or materials for in vivo MSC delivery, in a manner designed to specify the MSC paracrine activity and therapeutic effect. This would have enormous implications for the field, by providing the ability to systematically tailor the manufacturing method to match the desired protein or exosome populations produced for any specific clinical application.

Finally, we envision a likely role for biomaterials to aid in the delivery of paracrine factors or as a replacement for whole-cell implantation. An early example of the delivery concept is shown in a study by Zhang et al. who combined exosomes derived from MSCs with tricalcium phosphate scaffolds and demonstrated enhanced MSC osteogenesis and bone formation in a calvarial defect model [119]. The field of biomaterials offers many examples of controlled drug, protein, and liposome delivery, and the currently untapped potential of using these technologies to deliver defined paracrine factors is enormous. Exosome therapies also offer the exciting prospect of developing cell-free stem cell therapies and ultimately it may be possible to engineer synthetic exosomes with controlled therapeutic payloads, thereby providing therapies that could well be cheaper and more easily controlled than delivery of whole stem cell populations. Such a vision is a tantalizing prospect, but clearly, the field will have to develop much further to achieve such goals.

\section{Concluding Remarks}

In conclusion, it is clear from the reviewed literature that multiple aspects of the extracellular environment influence the MSC paracrine activity, both in terms of secreted proteins and exosomes. As technologies are developed to manufacture high-quality MSC products for clinical use, it is without doubt that advances in bioengineering and our understanding of how the extracellular environment affects the MSC paracrine activity will play a pivotal role in the generation of widespread, successful, clinical MSC therapies. Furthermore, integration of MSC biology with bio- materials science offers exciting promise to move beyond this to smart delivery of cell-free MSC-based therapies.

\section{Acknowledgments}

J.E.F. is supported by the Australian Research Council DECRA fellowship (DE13010098). R.L. is supported by the NHMRC project grant (GNT1083744) and the Fielding Foundation Fellowship.

\section{Author Disclosure Statement}

R.L. has filed a patent for the exosomes from amnion epithelial cells, National Application No. 2016901349. All the other authors declared no competing financial interests.

\section{References}

1. Daley GQ and DT Scadden. (2008). Prospects for stem cell-based therapy. Cell 132:544-548.

2. Hsiao ST-F, A Asgari, Z Lokmic, R Sinclair, GJ Dusting, SY Lim and RJ Dilley. (2012). Comparative analysis of paracrine factor expression in human adult mesenchymal stem cells derived from bone marrow, adipose, and dermal tissue. Stem Cells Dev 21:2189-2203.

3. Konala VBR, MK Mamidi, R Bhonde, AK Das, R Pochampally and R Pal. (2016). The current landscape of the mesenchymal stromal cell secretome: a new paradigm for cell-free regeneration. Cytotherapy 18:13-24.

4. da Silva Meirelles L, AM Fontes, DT Covas and AI Caplan. (2009). Mechanisms involved in the therapeutic properties of mesenchymal stem cells. Cytokine Growth Factor Rev 20:419-427.

5. de Girolamo L, E Lucarelli, G Alessandri, MA Avanzini, ME Bernardo, E Biagi, AT Brini, G D'Amico, F Fagioli, et al. (2013). Mesenchymal stem/stromal cells: a new cells as drugs' paradigm. Efficacy and critical aspects in cell therapy. Curr Pharm Des 19:2459-2473.

6. Pittenger MF. (1999). Multilineage potential of adult human mesenchymal stem cells. Science 284:143-147.

7. Erices A, P Conget and JJ Minguell. (2000). Mesenchymal progenitor cells in human umbilical cord blood. Br J Haematol 109:235-242.

8. Jiang Y, BN Jahagirdar, RL Reinhardt, RE Schwartz, CD Keene, XR Ortiz-Gonzalez, M Reyes, T Lenvik, T Lund, et al. (2002). Pluripotency of mesenchymal stem cells derived from adult marrow. Nature 418:41-49.

9. Gronthos S, M Mankani, J Brahim, PG Robey and S Shi. (2000). Postnatal human dental pulp stem cells (DPSCs) in vitro and in vivo. Proc Natl Acad Sci U S A 97:1362513630.

10. Gucciardo L, R Lories, N Ochsenbein-Kolble, E Done, A Zwijsen and J Deprest. (2009). Fetal mesenchymal stem cells: isolation, properties and potential use in perinatology and regenerative medicine. BJOG 116:166-172.

11. Manini I, L Gulino, B Gava, E Pierantozzi, C Curina, D Rossi, A Brafa, C D'Aniello and V Sorrentino. (2011). Multi-potent progenitors in freshly isolated and cultured human mesenchymal stem cells: a comparison between adipose and dermal tissue. Cell Tissue Res 344:85-95.

12. Kusuma GD, MH Abumaree, MD Pertile, AV Perkins, SP Brennecke and B Kalionis. (2016). Mesenchymal stem/ stromal cells derived from a reproductive tissue niche under oxidative stress have high aldehyde dehydrogenase activity. Stem Cell Rev Reports 12:285-297. 
13. Kusuma GD, D Menicanin, S Gronthos, U Manuelpillai, MH Abumaree, MD Pertile, SP Brennecke and B Kalionis. (2015). Ectopic bone formation by mesenchymal stem cells derived from human term placenta and the decidua. PLoS One 10:e141246.

14. Meirelles L da S, PC Chagastelles and NB Nardi. (2006). Mesenchymal stem cells reside in virtually all post-natal organs and tissues. J Cell Sci 119:2204-2213.

15. Dominici M, K Le Blanc, I Mueller, I Slaper-Cortenbach, F Marini, D Krause, R Deans, A Keating, D Prockop and E Horwitz. (2006). Minimal criteria for defining multipotent mesenchymal stromal cells. The International Society for Cellular Therapy position statement. Cytotherapy 8:315-317.

16. Frith JE, AR Cameron, DJ Menzies, P Ghosh, DL Whitehead, S Gronthos, ACW Zannettino and JJ Cooper-White. (2013). An injectable hydrogel incorporating mesenchymal precursor cells and pentosan polysulphate for intervertebral disc regeneration. Biomaterials 34:9430-9440.

17. Arthur A, A Zannettino and S Gronthos. (2009). The therapeutic applications of multipotential mesenchymal/ stromal stem cells in skeletal tissue repair. J Cell Physiol 218:237-245.

18. Karam JP, C Muscari and CN Montero-Menei. (2012). Combining adult stem cells and polymeric devices for tissue engineering in infarcted myocardium. Biomaterials 33:5683-5695.

19. Kim J, WG Bae, HW Choung, KT Lim, H Seonwoo, HE Jeong, KY Suh, NL Jeon, PH Choung and JH Chung. (2014). Multiscale patterned transplantable stem cell patches for bone tissue regeneration. Biomaterials 35:90589067.

20. Dahlin RL, LA Kinard, J Lam, CJ Needham, S Lu, FK Kasper and AG Mikos. (2014). Articular chondrocytes and mesenchymal stem cells seeded on biodegradable scaffolds for the repair of cartilage in a rat osteochondral defect model. Biomaterials 35:7460-7469.

21. Galderisi U and A Giordano. (2012). The gap between the physiological and therapeutic roles of mesenchymal stem cells. Med Res Rev 29:1292-1327.

22. Minguell JJ, C Allers and GP Lasala. (2013). Mesenchymal stem cells and the treatment of conditions and diseases: the less glittering side of a conspicuous stem cell for basic research. Stem Cells Dev 22:193-203.

23. Karp JM and GS Leng Teo. (2009). Mesenchymal stem cell homing: the devil is in the details. Cell Stem Cell 4:206-216.

24. Wagner J, T Kean, R Young, JE Dennis and AI Caplan. (2009). Optimizing mesenchymal stem cell-based therapeutics. Curr Opin Biotechnol 20:531-536.

25. Freyman T, G Polin, H Osman, J Crary, M Lu, L Cheng, M Palasis and RL Wilensky. (2006). A quantitative, randomized study evaluating three methods of mesenchymal stem cell delivery following myocardial infarction. Eur Heart J 27:1114-1122.

26. Park CW, K-S Kim, S Bae, HK Son, P-K Myung, HJ Hong and H Kim. (2009). Cytokine secretion profiling of human mesenchymal stem cells by antibody array. Int $\mathbf{J}$ Stem Cells 2:59-68.

27. Caplan AI and D Correa. (2011). The MSC: an injury drugstore. Cell Stem Cell 9:11-15.

28. Gnecchi M, P Danieli, G Malpasso and MC Ciuffreda. (2016). Paracrine mechanisms of mesenchymal stem cells in tissue repair. In Mesenchymal Stem Cells: Methods and
Protocols. Gnecchi M, ed. Springer, New York, pp 123146.

29. Maguire G. (2013). Stem cell therapy without the cells. Commun Integr Biol 6:e26631.

30. Haynesworth SE, MA Baber and AI Caplan. (1996). Cytokine expression by human marrow-derived mesenchymal progenitor cells in vitro: effects of dexamethasone and IL-1 alpha. J Cell Physiol 166:585-592.

31. Patschan D, M Plotkin and MS Goligorsky. (2006). Therapeutic use of stem and endothelial progenitor cells in acute renal injury: ca ira. Curr Opin Pharmacol 6:176-183.

32. Tögel F, Z Hu and K Weiss. (2005). Administered mesenchymal stem cells protect against ischemic acute renal failure through differentiation-independent mechanisms. Am J Physiol Ren Physiol 289:31-42.

33. Gnecchi M, H He, N Noiseux, OD Liang, L Zhang, F Morello, H Mu, LG Melo, RE Pratt, JS Ingwall and VJ Dzau. (2006). Evidence supporting paracrine hypothesis for Akt-modified mesenchymal stem cell-mediated cardiac protection and functional improvement. FASEB J 20:661-669.

34. Timmers L, SK Lim, F Arslan, JS Armstrong, IE Hoefer, PA Doevendans, JJ Piek, RM El Oakley, A Choo, et al. (2008). Reduction of myocardial infarct size by human mesenchymal stem cell conditioned medium. Stem Cell Res 1:129-137.

35. Gnecchi M, Z Zhang, A Ni and VJ Dzau. (2008). Paracrine mechanisms in adult stem cell signaling and therapy. Circ Res 103:1204-1219.

36. Kuraitis D, C Giordano, M Ruel, A Musarò and EJ Suuronen. (2012). Exploiting extracellular matrix-stem cell interactions: a review of natural materials for therapeutic muscle regeneration. Biomaterials 33:428-443.

37. Khubutiya MS, AV Vagabov, AA Temnov and AN Sklifas. (2014). Paracrine mechanisms of proliferative, anti-apoptotic and anti-inflammatory effects of mesenchymal stromal cells in models of acute organ injury. Cytotherapy 16:579-585.

38. Carayon K, K Chaoui, E Ronzier, I Lazar, J BertrandMichel, V Roques, S Balor, F Terce, A Lopez, L Salomé and E Joly. (2011). Proteolipidic composition of exosomes changes during reticulocyte maturation. J Biol Chem 286:34426-34439.

39. Anderson JD, HJ Johansson, CS Graham, M Vesterlund, MT Pham, CS Bramlett, EN Montgomery, MS Mellema, RL Bardini, et al. (2016). Comprehensive proteomic analysis of mesenchymal stem cell exosomes reveals modulation of angiogenesis via nuclear factor-kappaB signaling. Stem Cells 34:601-613.

40. Raposo G and W Stoorvogel. (2013). Extracellular vesicles: exosomes, microvesicles, and friends. J Cell Biol 200:373-383.

41. Xu R, DW Greening, H-J Zhu, N Takahashi and RJ Simpson. (2016). Extracellular vesicle isolation and characterization: toward clinical application. J Clin Invest 126:1152-1162.

42. Baglio SR, K Rooijers, D Koppers-Lalic, FJ Verweij, M Pérez Lanzón, N Zini, B Naaijkens, F Perut, HW Niessen, N Baldini and DM Pegtel. (2015). Human bone marrowand adipose-mesenchymal stem cells secrete exosomes enriched in distinctive miRNA and tRNA species. Stem Cell Res Ther 6:127.

43. Lobb RJ, M Becker, SW Wen, CSF Wong, AP Wiegmans, A Leimgruber and A Möller. (2015). Optimized exosome 
isolation protocol for cell culture supernatant and human plasma. J Extracell Vesicles 1:1-11.

44. Lener T, M Gioma, L Aigner, V Börger, E Buzas, G Camussi, N Chaput, D Chatterjee, FA Court, et al. (2015). Applying extracellular vesicles based therapeutics in clinical trials-an ISEV position paper. J Extracell Vesicles 4:1-31.

45. Lötvall J, AF Hill, F Hochberg, EI Buzás, D Di Vizio, C Gardiner, YS Gho, IV Kurochkin, S Mathivanan, et al. (2014). Minimal experimental requirements for definition of extracellular vesicles and their functions: a position statement from the International Society for Extracellular Vesicles. J Extracell Vesicles 3:26913.

46. Sinclair KA, S Yerkovich, P Hopkins and D Chambers. (2016). 20-Human lung-derived mesenchymal stromal cells donate cytoplasmic content to bronchial epithelium through microtubules, tunnelling nanotubes, gap junctions and microvesicles. Cytotherapy 18:S13.

47. Matula Z, A Németh, P Lőrincz, A Szepesi, B Anna, EI Buzás, P Lőw, K Német, F Uher and V Urbán. (2016). The role of extracellular vesicle and tunneling nanotubemediated intercellular cross-talk between mesenchymal stem cells and human peripheral T cells. Stem Cells Dev 25:1818-1832.

48. Furuta T, S Miyaki, H Ishitobi, T Ogura, Y Kato, N Kamei, K Miyado, Y Higashi and M Ochi. (2012). Mesenchymal stem cell-derived exosomes promote fracture healing in a mouse model. Stem Cells Transl Med 5:1-11.

49. Wen S, M Dooner, Y Cheng, E Papa, M Del Tatto, M Pereira, Y Deng, L Goldberg, J Aliotta, et al. (2016). Mesenchymal stromal cell derived extracellular vesicles rescue radiation damage to murine marrow hematopoietic cells. Leukemia 30:1-39.

50. Zhang S, WC Chu, RC Lai, SK Lim, JHP Hui and WS Toh. (2016). Exosomes derived from human embryonic mesenchymal stem cells promote osteochondral regeneration. Osteoarthritis Cartilage 24:6-11.

51. Arslan F, RC Lai, MB Smeets, L Akeroyd, A Choo, ENE Aguor, L Timmers, HV van Rijen, PA Doevendans, et al. (2013). Mesenchymal stem cell-derived exosomes increase ATP levels, decrease oxidative stress and activate PI3K/Akt pathway to enhance myocardial viability and prevent adverse remodeling after myocardial ischemia/ reperfusion injury. Stem Cell Res 10:301-312.

52. Feng Y, W Huang, M Wani, X Yu and M Ashraf. (2014). Ischemic preconditioning potentiates the protective effect of stem cells through secretion of exosomes by targeting Mecp2 via miR-22. PLoS One 9:e88685.

53. Yu B, HW Kim, M Gong, J Wang, RW Millard, Y Wang, M Ashraf and M Xu. (2015). Exosomes secreted from GATA-4 overexpressing mesenchymal stem cells serve as a reservoir of anti-apoptotic microRNAs for cardioprotection. Int J Cardiol 182:349-360.

54. Wang B, K Yao, BM Huuskes, H-H Shen, J Zhuang, C Godson, EP Brennan, JL Wilkinson-Berka, AF Wise and SD Ricardo. (2016). Mesenchymal stem cells deliver exogenous microRNA-let7c via exosomes to attenuate renal fibrosis. Mol Ther 24:1290-1301.

55. Choi M, T Ban and T Rhim. (2014). Therapeutic use of stem cell transplantation for cell replacement or cytoprotective effect of microvesicle released from mesenchymal stem cell. Mol Cells 37:133-139.

56. Hyun J, S Wang, J Kim, GJ Kim and Y Jung. (2015). MicroRNA125b-mediated Hedgehog signaling influences liver regeneration by chorionic plate-derived mesenchymal stem cells. Sci Rep 5:14135.

57. Li T, Y Yan, B Wang, H Qian, X Zhang, L Shen, M Wang, Y Zhou, W Zhu, W Li and W Xu. (2012). Exosomes derived from human umbilical cord mesenchymal stem cells alleviate liver fibrosis. Stem Cells Dev 22:845854.

58. Kalra H, GPC Drummen and S Mathivanan. (2016). Focus on extracellular vesicles: introducing the next small big thing. Int J Mol Sci 17:170.

59. Iavello A, VSL Frech, C Gai, MC Deregibus, PJ Quesenberry and G Camussi. (2016). Role of Alix in miRNA packaging during extracellular vesicle biogenesis. Int $\mathrm{J}$ Mol Med 37:958-966.

60. Baietti MF, Z Zhang, E Mortier, A Melchior, G Degeest, A Geeraerts, Y Ivarsson, F Depoortere, C Coomans, et al. (2012). Syndecan-syntenin-ALIX regulates the biogenesis of exosomes. Nat Cell Biol 14:677-685.

61. Biancone L, S Bruno, MC Deregibus, C Tetta and G Camussi. (2012). Therapeutic potential of mesenchymal stem cell-derived microvesicles. Nephrol Dial Transplant 27:3037-3042.

62. del Rio A, R Perez-Jimenez, R Liu, P Roca-Cusachs, JM Fernandez and MP Sheetz. (2009). Stretching single talin rod molecules activates vinculin binding. Science 323: 638-641.

63. Tamada M, MP Sheetz and Y Sawada. (2004). Activation of a signaling cascade by cytoskeleton stretch. Dev Cell 7:709-718.

64. Sawada Y, M Tamada, BJ Dubin-Thaler, O Cherniavskaya, R Sakai, S Tanaka and MP Sheetz. (2006). Force sensing by mechanical extension of the Src family kinase substrate p130Cas. Cell 127:1015-1026.

65. Burridge K and M Chrzanowska-Wodnicka. (1996). Focal adhesions, contractility, and signaling. Annu Rev Cell Dev Biol 12:463-519.

66. McBeath R, DM Pirone, CM Nelson, K Bhadriraju and CS Chen. (2004). Cell shape, cytoskeletal tension, and RhoA regulate stem cell lineage commitment. Dev Cell 6:483495.

67. Chrzanowska-Wodnicka M and K Burridge. (1996). Rhostimulated contractility drives the formation of stress fibers and focal adhesions. J Cell Biol 133:1403-1415.

68. Miyauchi T, T Yanagida and Y Sako. (2007). Rho small GTPase regulates the stability of individual focal adhesions: a FRET-based visualization of GDP/GTP exchange on small GTPases. Biophysics (Oxf) 28:63-73.

69. Li C, G Zhen, Y Chai, L Xie, JL Crane, E Farber, CR Farber, X Luo, P Gao, X Cao and M Wan. (2016). RhoA determines lineage fate of mesenchymal stem cells by modulating CTGF-VEGF complex in extracellular matrix. Nat Commun 7:11455.

70. Sims JR, S Karp and DE Ingber. (1992). Altering the cellular mechanical force balance results in integrated changes in cell, cytoskeletal and nuclear shape. J Cell Sci 103:1215-1222.

71. Maniotis AJ, CS Chen and DE Ingber. (1997). Demonstration of mechanical connections between integrins, cytoskeletal filaments, and nucleoplasm that stabilize nuclear structure. Proc Natl Acad Sci U S A 94:849-854.

72. Starr DA and HN Fridolfsson. (2010). Interactions between nuclei and the cytoskeleton are mediated by SUNKASH nuclear-envelope bridges. Annu Rev Cell Dev Biol 26:421-444. 
73. Lammerding J, PC Schulze, T Takahashi, S Kozlov, T Sullivan, RD Kamm, CL Stewart and RT Lee. (2004). Lamin A/C deficiency causes defective nuclear mechanics and mechanotransduction. J Clin Invest 113:370-378.

74. Lammerding J, J Hsiao, PC Schulze, S Kozlov, CL Stewart and RT Lee. (2005). Abnormal nuclear shape and impaired mechanotransduction in emerin-deficient cells. J Cell Biol 170:781-791.

75. Ho CY, DE Jaalouk, MK Vartiainen and J Lammerding. (2013). Lamin A/C and emerin regulate MKL1-SRF activity by modulating actin dynamics. Nature 497:507-511.

76. Zhang M, Y Liao and B Lönnerdal. (2016). EGR-1 is an active transcription factor in TGF- $\beta 2$-mediated small intestinal cell differentiation. J Nutr Biochem 37:101-108.

77. Pires AO, B Mendes-Pinheiro, FG Teixeira, SI Anjo, S Ribeiro-Samy, ED Gomes, SC Serra, NA Silva, B Manadas, N Sousa and AJ Salgado. (2016). Unveiling the differences of secretome of human bone marrow mesenchymal stem cells, adipose tissue derived stem cells and human umbilical cord perivascular cells: a proteomic analysis. Stem Cells Dev 25:1073-1083.

78. Blaber SP, RA Webster, CJ Hill, EJ Breen, D Kuah, G Vesey and BR Herbert. (2012). Analysis of in vitro secretion profiles from adipose-derived cell populations. J Transl Med 10:172.

79. Amable PR, MVT Teixeira, RBV Carias, JM Granjeiro and R Borojevic. (2014). Protein synthesis and secretion in human mesenchymal cells derived from bone marrow, adipose tissue and Wharton's jelly. Stem Cell Res Ther 5:53.

80. Wang B, YW Lee, B Huang, J Zhang, T Wu, X Jiang, R Wang and G Li. (2016). Secretome of human fetal mesenchymal stem cell ameliorates replicative senescence. Stem Cells Dev 25:1755-1766.

81. Pandey AC, JA Semon, D Kaushal, RP O'Sullivan, J Glowacki, JM Gimble and BA Bunnell. (2011). MicroRNA profiling reveals age-dependent differential expression of nuclear factor $\kappa \mathrm{B}$ and mitogen-activated protein kinase in adipose and bone marrow-derived human mesenchymal stem cells. Stem Cell Res Ther 2:49.

82. Ganguly P, JJ El-Jawhari, PV Giannoudis, AN Burska, F Ponchel and EA Jones. (2017). Age related changes in bone marrow mesenchymal stromal cells: a potential impact on osteoporosis and osteoarthritis development. Cell Transplant [Epub ahead of print]; DOI: 10.3727/096368917X694651.

83. Billing AM, H Ben Hamidane, SS Dib, RJ Cotton, AM Bhagwat, P Kumar, S Hayat, NA Yousri, N Goswami, et al. (2016). Comprehensive transcriptomic and proteomic characterization of human mesenchymal stem cells reveals source specific cellular markers. Sci Rep 6:21507.

84. Panfoli I, S Ravera, M Podesta, C Cossu, L Santucci, M Bartolucci, M Bruschi, D Calzia, F Sabatini, et al. (2016). Exosomes from human mesenchymal stem cells conduct aerobic metabolism in term and preterm newborn infants. FASEB J 30:1416-1424.

85. Arufe MC, A De la Fuente, J Mateos, I Fuentes, FJ De Toro and FJ Blanco. (2011). Analysis of the chondrogenic potential and secretome of mesenchymal stem cells derived from human umbilical cord stroma. Stem Cells Dev 20:1199-1212.

86. Choi YA, J Lim, KM Kim, B Acharya, JY Cho, YC Bae, HI Shin, SY Kim and EK Park. (2010). Secretome analysis of human BMSCs and identification of SMOC1 as an important ECM protein in osteoblast differentiation. J Proteome Res 9:2946-2956.
87. Hemmingsen M, S Vedel, P Skafte-Pedersen, D Sabourin, P Collas, H Bruus and M Dufva. (2013). The role of paracrine and autocrine signaling in the early phase of adipogenic differentiation of adipose-derived stem cells. PLoS One 8:e63638.

88. Frith JE, DM Titmarsh, H Padmanabhan and JJ CooperWhite. (2013). Microbioreactor array screening of wnt modulators and microenvironmental factors in osteogenic differentiation of mesenchymal progenitor cells. PLoS One 8:e82931.

89. Ren G, L Zhang, X Zhao, G Xu, Y Zhang, AI Roberts, RC Zhao and Y Shi. (2008). Mesenchymal stem cell-mediated immunosuppression occurs via concerted action of chemokines and nitric oxide. Cell Stem Cell 2:141-150.

90. Li C, G Li, M Liu, T Zhou and H Zhou. (2016). Paracrine effect of inflammatory cytokine-activated bone marrow mesenchymal stem cells and its role in osteoblast function. J Biosci Bioeng 121:213-219.

91. Rodriguez T, A Saldias, M Irigo, J Zamora, M Perone and R Dewey. (2014). Effect of TGF-b1 stimulation on the secretome of human adipose-derived mesenchymal stromal cells. Stem Cells Transl Med 4:481-488.

92. Nemeth K, A Keane-myers, M Jared, DD Metcalfe, JD Gorham, VG Bundoc, MG Hodges, I Jelinek, S Madala, et al. (2010). Bone marrow stromal cells use TGF-beta to suppress allergic responses in a mouse model of ragweedinduced asthma. Erratum in Proc Natl Acad Sci U S A 107:8041.

93. Ti D, H Hao, C Tong, J Liu, L Dong, J Zheng, Y Zhao, H Liu, X Fu and W Han. (2015). LPS-preconditioned mesenchymal stromal cells modify macrophage polarization for resolution of chronic inflammation via exosomeshuttled let-7b. J Transl Med 13:308.

94. Holzwarth C, M Vaegler, F Gieseke, SM Pfister, R Handgretinger, G Kerst and I Muller. (2010). Low physiologic oxygen tensions reduce proliferation and differentiation of human multipotent mesenchymal stromal cells. BMC Cell Biol 11:11.

95. Hung S-P, JH Ho, YR Shih, T Lo and OK Lee. (2012). Hypoxia promotes proliferation and osteogenic differentiation potentials of human mesenchymal stem cells. J Orthop Res 30:260-266.

96. Teixeira FG, KM Panchalingam, SI Anjo, B Manadas, R Pereira, N Sousa, AJ Salgado and LA Behie. (2015). Do hypoxia/normoxia culturing conditions change the neuroregulatory profile of Wharton Jelly mesenchymal stem cell secretome? Stem Cell Res Ther 6:133.

97. Paquet J, M Deschepper, A Moya, D LogeartAvramoglou, C Boisson-Vidal and H Petite. (2015). Oxygen tension regulates human mesenchymal stem cell paracrine functions. Stem Cells Transl Med 4:809-821.

98. An HY, HS Shin, JS Choi, HJ Kim, JY Lim and YM Kim. (2015). Adipose mesenchymal stem cell secretome modulated in hypoxia for remodeling of radiation-induced salivary gland damage. PLoS One 10:1-17.

99. Saraswati S, Y Guo, J Atkinson and PP Young. (2015). Prolonged hypoxia induces monocarboxylate transporter4 expression in mesenchymal stem cells resulting in a secretome that is deleterious to cardiovascular repair. Stem Cells 33:1333-1344.

100. Li L, S Jin and Y Zhang. (2015). Ischemic preconditioning potentiates the protective effect of mesenchymal stem cells on endotoxin-induced acute lung injury in mice through secretion of exosome. Int J Clin Exp Med 8:3825-3832. 
101. Ylöstalo JH, TJ Bartosh, K Coble and DJ Prockop. (2012). Human mesenchymal stem/stromal cells cultured as spheroids are self-activated to produce prostaglandin E2 that directs stimulated macrophages into an anti-inflammatory phenotype. Stem Cells 30:2283-2296.

102. Bartosh TJ, JH Ylöstalo, A Mohammadipoor, N Bazhanov, K Coble, K Claypool, RH Lee, H Choi and DJ Prockop. (2010). Aggregation of human mesenchymal stromal cells (MSCs) into 3D spheroids enhances their antiinflammatory properties. Proc Natl Acad Sci U S A 107:13724-13729.

103. Frith JE, B Thomson and PG Genever. (2010). Dynamic three-dimensional culture methods enhance mesenchymal stem cell properties and increase therapeutic potential. Tissue Eng Part C Methods 16:735-749.

104. Ho SS, KC Murphy, BYK Binder, CB Vissers and JK Leach. (2014). Increased survival and function of mesenchymal stem cell spheroids entrapped in instructive alginate hydrogels. Stem Cells Transl Med 5:773781.

105. De Lisio M, T Jensen, RA Sukiennik, HD Huntsman and M Boppart. (2014). Substrate and strain alter the musclederived mesenchymal stem cell secretome to promote myogenesis. Stem Cell Res Ther 5:74.

106. Chaudhuri O, L Gu, D Klumpers, M Darnell, SA Bencherif, JC Weaver, N Huebsch, H-P Lee, E Lippens, GN Duda and DJ Mooney. (2015). Hydrogels with tunable stress relaxation regulate stem cell fate and activity. Nat Mater 15:326-333.

107. Cameron AR, JE Frith and JJ Cooper-White. (2011). The influence of substrate creep on mesenchymal stem cell behaviour and phenotype. Biomaterials 32:5979-5993.

108. Engler AJ, S Sen, HL Sweeney and DE Discher. (2006). Matrix elasticity directs stem cell lineage specification. Cell 126:677-689.

109. Frith JE, RJ Mills and JJ Cooper-White. (2012). Lateral spacing of adhesion peptides influences human mesenchymal stem cell behaviour. J Cell Sci 125:317-327.

110. Wu YN, JBK Law, AY He, HY Low, JHP Hui, CT Lim, Z Yang and EH Lee. (2014). Substrate topography determines the fate of chondrogenesis from human mesenchymal stem cells resulting in specific cartilage phenotype formation. Nanomedicine 10:1507-1516.

111. Tsimbouri P, N Gadegaard, K Burgess, K White, P Reynolds, P Herzyk, R Oreffo and MJ Dalby. (2014). Nanotopographical effects on mesenchymal stem cell morphology and phenotype. J Cell Biochem 115:380-390.

112. Abdeen AA, JB Weiss, J Lee and KA Kilian. (2014). Matrix composition and mechanics direct proangiogenic signaling from mesenchymal stem cells. Tissue Eng Part A 20:2737-2745.
113. Kasper G, N Dankert, J Tuischer, M Hoeft, T Gaber, JD Glaeser, D Zander, M Tschirschmann, M Thompson, G Matziolis and GN Duda. (2007). Mesenchymal stem cells regulate angiogenesis according to their mechanical environment. Stem Cells 25:903-910.

114. Gardner OF, N Fahy, M Alini and MJ Stoddart. (2016). Differences in human mesenchymal stem cell secretomes during chondrogenic induction. Eur Cell Mater 31:221235.

115. Kilian KA, B Bugarija, BT Lahn and M Mrksich. (2010). Geometric cues for directing the differentiation of mesenchymal stem cells. Proc Natl Acad Sci U S A 107:48724877.

116. Frith JE, P Jaramillo-Ferrada, RJ Mills, AR Cameron, DM Titmarsh, EJ Wolvetang and JJ Cooper-White. (2012). Development of defined culture conditions for expansion of human mesenchymal stromal cells for clinical applications. In: Stem Cells and Cancer Stem Cells, Volume 8: Therapeutic Applications in Disease and Injury. Hayat MA, ed. Springer, Dordrecht, Netherlands, pp 13-26.

117. Swamynathan P, P Venugopal, S Kannan, C Thej, UK Kolkundar, S Bhagwat, M Ta, A Sen Majumdar and S Balasubramanian. (2014). Are serum-free and xeno-free culture conditions ideal for large scale clinical grade expansion of Wharton's jelly derived mesenchymal stem cells? A comparative study. Stem Cell Res Ther 5:88.

118. de Soure AM, A Fernandes-Platzgummer, CL da Silva and JMS Cabral. (2016). Scalable microcarrier-based manufacturing of mesenchymal stem/stromal cells. J Biotechnol 236:88-109.

119. Zhang J, X Liu, H Li, C Chen, B Hu, X Niu, Q Li, B Zhao, Z Xie and Y Wang. (2016). Exosomes/tricalcium phosphate combination scaffolds can enhance bone regeneration by activating the PI3K/Akt signaling pathway. Stem Cell Res Ther 7:136.

Address correspondence to: Jessica E. Frith, PhD

Department of Materials Science and Engineering Monash University 22 Alliance Lane Clayton 3800 Victoria Australia

E-mail: jessica.frith@monash.edu

Received for publication December 14, 2016 Accepted after revision February 9, 2017

Prepublished on Liebert Instant Online February 10, 2017 